\title{
Pengaruh Suhu Tuang dan Cetakan Pengecoran Aluminium Bekas Menggunakan Gravity Die Casting terhadap Kecacatan
}

\author{
Untung Sukamto ${ }^{1}$ dan Muhammad Fauzan Bawono Putra ${ }^{2}$ \\ Jurusan Teknik Pertambangan - Program Studi Teknik Metalurgi \\ UPN “ Veteran " Yogyakarta \\ J1. Babarsari 2 Tambakbayan, Yogyakarta, 55281, Indonesia. \\ E-mail: cak_oen2000@yahoo.com¹; fauzanputrab@gmail.com²; \\ (082136054123)
}

\begin{abstract}
Abstrak
Pengecoran dilakukan dengan cetakan permanen. Penelitian dilakukan pengecoran untuk menghasilkan produk berupa logo Universitas Pembangunan Nasional "Veteran" Yogyakarta berukuran $30 \mathrm{~cm}$ dengan ketebalan $1 \mathrm{~cm}$ menggunakan aluminium bekas berupa piston yang sudah tidak terpakai. Berbahan dasar paduan aluminum cor seri $3 \mathrm{xx}$ yang berfokus pada parameter suhu cetakan, dan suhu peleburan.

Pre-heat terhadap tungku selama 45 menit hingga 1 jam. Dengan suhu peleburan yang digunakan $650^{\circ} \mathrm{C}$, dan $750^{\circ} \mathrm{C}$. Parameter suhu cetakan digunakan pada saat cetakan bersuhu ruang, $150^{\circ} \mathrm{C}, 170^{\circ} \mathrm{C}$, dan $230^{\circ} \mathrm{C}$. Melalui pengamatan makro sudah cukup untuk menentukan penyebab dari kegagalan pengecoran yang terjadi untuk produk ini.

Setelah penelitian dilakukan terdapat banyak kendala terhadap suhu penuangan di $750^{\circ} \mathrm{C}$ dimana terak yang terbentuk lebih banyak menimbulkan permukaan kasar. Hasil dari penuangan yang lambat menimbulkan pengecoran tidak sempurna dan dilakukan berkali-kali pada suhu tuang ini. Suhu tuang $650^{\circ} \mathrm{C}$ ditunjukkan hasil yang cukup baik tanpa pengulangan pengecoran, dan didapatkan permukaan yang halus dengan kecacatan yang sedikit. Suhu cetakan dengan hasil paling baik ditunjukkan pada suhu $150^{\circ} \mathrm{C}$. Pada suhu tersebut didapatkan kecacatan yang paling minimum dibandingkan suhu cetakan lainnya, cacat yang muncul dalam suhu ini hanya berupa cold shut dan sebuah bercak hitam dibagian depan hasil coran.
\end{abstract}

Kata Kunci : Pengecoran, Aluminium Bekas, Suhu Peleburan, Suhu Cetakan, Cacat

\begin{abstract}
In this study permanent mold is used for the casting process. In this research, foundry was carried out to produce a product in the form for the logo of Universitas Pembangunan Nasional "Veteran" Yogyakarta measuring $30 \mathrm{~cm}$ using aluminum scrap in the form of an unused piston made of 3xx series aluminum alloy which focuses on the parameters of the mold temperature, and the melting temperature.

Pre-heating the furnace for 45 minutes to 1 hour. The melting temperatures used were $650^{\circ} \mathrm{C}$, and $750^{\circ} \mathrm{C}$. The mold temperature parameters were used when the mold was at room temperature, $150^{\circ} \mathrm{C}, 170^{\circ} \mathrm{C}$, and $230^{\circ} \mathrm{C}$. Macro observations were sufficient to determine the cause of the casting failure that occurred for this product.

After the research was carried out, there were many obstacles to the pouring temperature at $750^{\circ} \mathrm{C}$ where the slag formed caused more surface roughness. The result of slow pouring causes imperfect casting and is carried out many times at this pouring temperature. The casting temperature of $650^{\circ} \mathrm{C}$ showed quite good results without repeated casting, and a smooth surface was obtained with few defects. The temperature of the mold with the best results is shown at a temperature of $150^{\circ} \mathrm{C}$. At this temperature, the minimum defects are obtained compared to other mold temperatures, the defects that appear at this temperature are only cold shuts and a black spot on the front of the casting.
\end{abstract}

Keywords: Casting, Aluminum Scrap, Melting Temperature, Mold Temperature, Defect 


\section{Pendahuluan}

Indonesia menyumbang sampah secara nasional sebesar 175.000 ton per harinya. Dengan komposisi sampah logam berkisar 4,3\% (Kementerian Lingkungan Hidup dan Kehutanan (KLHK), 2017). Angka timbunan sampah logam ini dapat dikurangi di Indonesia salah satunya dengan mendaur ulang logam menggunakan tahap metalurgi berupa pengecoran.

Metode gravity die casting digunakan dalam proses daur ulang aluminium bekas, dengan menggunakan prinsip penuangan menggunakan gaya gravitasi dan cetakan permanen. Dengan demikian diperlukan cetakan (mold) yang terbuat dari logam besi. Cetakan pada pengecoran aluminium bekas harus didesain dengan memperhatikan penyusutan logam cair sehingga hasil coran sesuai dengan dimensi yang dibutuhkan. Disamping pengaruh cetakan yang baik, kesempurnaan hasil coran juga dipengaruhi suhu tuang logam cair, suhu cetakan serta laju penuangan. Parameter yang tepat akan menentukan kualitas dan kekonsistenan hasil pengecoran dengan demikian perlu dilakukan dengan penelitian untuk mendapatkan suhu tuang dan suhu cetakan yang tepat. Pengecoran berjalan dengan baik perlu mempertimbangkan berbagai hal yang telah disebutkan dengan demikian didapatkan hasil yang maksimal.

\section{Metode Penelitian}

Metode yang diguanakan merupakan gravity die casting. Parameter pengecoran die casting yaitu suhu peleburan dengan suhu $650^{\circ} \mathrm{C}$ dan $750^{\circ} \mathrm{C}$. Dan suhu cetakan bersuhu ruang, $150^{\circ} \mathrm{C}, 170^{\circ} \mathrm{C}$, dan $230^{\circ} \mathrm{C}$. Parameter yang dijaga tetap pada penelitian ini yaitu kemiringan cetakan antara $75^{\circ}$ hingga $80^{\circ}$. Hal yang dapat berubah dalam penelitian ini adalah cara penuangan operator penuangan dengan setiap pengegecoran berbeda kondisi. Terdapat 2 operator bekerja sama untuk menuang agar mempermudah beban, dan ada yang dilakukan sendiri. Kemampuan operator dalam menuang berbeda dapat menunjukkan hasil yang berbeda. Analisis yang dilakukan menggunakan pengamatan visual. Sampel yang digunakan merupakan piston bekas berbahan dasar aluminium paduan cor seri 3xx. Dengan kandungan utama Al-Mg-Si. Lokasi penelitian dilakukan di Laboratorium Pirometalurgi UPN "Veteran" Yogyakarta tahun 2021.

\section{Hasil Penelitian dan Pembahasan}

Suhu tuang $650^{\circ} \mathrm{C}$ tanpa adanya pre-heat pada cetakan didapatkan hasil penuangan dilakukan seorang diri. Pada saat penuangan terjadi kesulitan, dimana crucible harus dimiringkan hampir $90^{\circ}$ yang membuat penuangan terhenti dan menimbulkan incomplete casting dimana keseluruhan logam cair tidak terisi penuh pada cetakan. Flash yang terjadi pada bagian atas disebabkan karena cetakan yang kurang rapat sehingga menimbulkan celah pada coran kemudian logam cair mengisi rongga pada bagian tersebut. Pada bagian belakang terjadi penuangan terjadi cold shut. Penyesuaian operator dalam menuang membuat penuangangan berhenti sementara. Kecacatan cold shut dalam percobaan ini diabaikan diakarenakan hanya ditimbulkan pada bagian belakang, 
dengan tujuan utama bagian depan berupa logo dan tulisan terlihat cukup jelas. Shrinkage disebabkan oleh kandungan air pada semen yang menguap sehingga menghambat pengisisan aluminium terhadap hasil coran. Hasil itunjukkan pada Gambar 1.

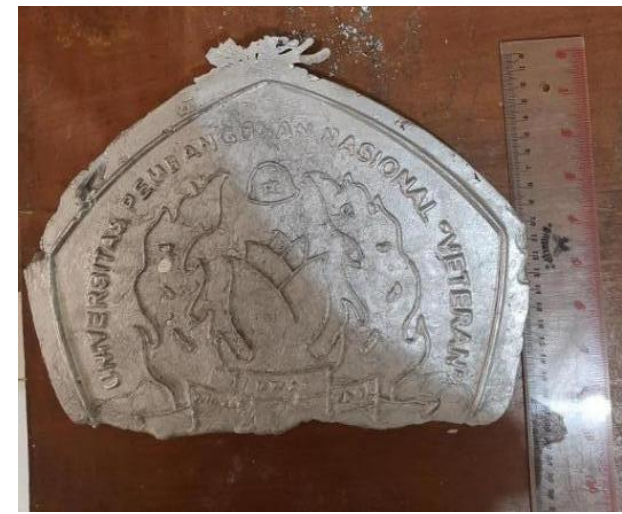

Gambar 1.

Suhu Tuang $650^{\circ} \mathrm{C}$, Suhu Ruang Cetakan Sumber: didapatkan dari penelitian, 2021

Suhu tuang $650^{\circ} \mathrm{C}$, suhu cetakan $150^{\circ} \mathrm{C}$ pada bagian atas hasil pengecoran terdapat hasil cold shut yang sangat fatal. Pada saat penuangan operator mencoba menuang sendiri namun dikarenakan penuangan terlalu berat operator berhenti menuang sejenak kemudian dibantu untuk menuang kelanjutannya. Cold shut lain juga terbentuk pada bagian bawah hasil pengecoran yang sedikit. Flash juga ditimbulkan pada hasil ini karena cetakan kurang rapat. Porositas berukuran kurang lebih $1 \mathrm{~mm}$ pada bagian depan coran. Terdapat retak pada bagian bawah hasil pengecoran kemungkinan dikarenakan pada bagian tersebut suhu cetakan turun sehingga terbentuk retakan karena pendinginan yang terlalu cepat. Hasil ditunjukkan Gambar 2.

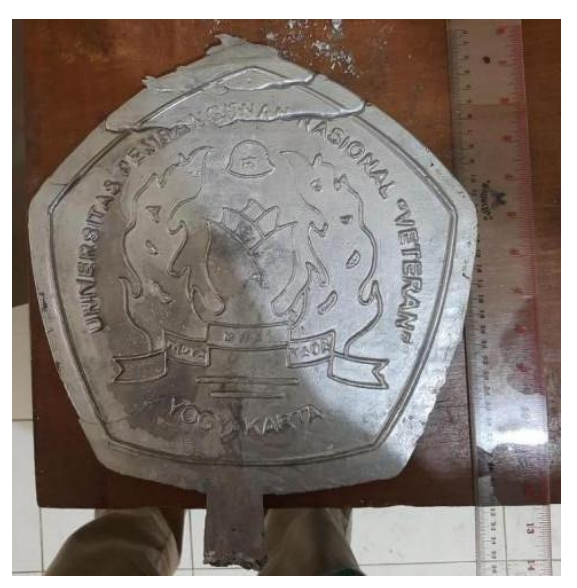

Gambar 2.

Suhu Tuang $650^{\circ} \mathrm{C}$, Suhu Cetakan $150^{\circ} \mathrm{C}$ Sumber: didapatkan dari penelitian, 2021 Pada hasil Suhu tuang $650^{\circ} \mathrm{C}$, Suhu cetakan $170^{\circ} \mathrm{C}$ yang diberikan terdapat kecacatan berupa cold shut pada sisi kiri dikarenakan saat penuangan harus menyesuaikan lagi antara 2 orang yang menuang sehingga terhenti sejenak. Crack serta misrun didapatkan dari kemungkinan pemerataan pre-heat cetakan yang tidak merata maupun adanya penyusutan dibagian tersebut. Patahan yang terjadi dikarenakan saat membuka hasil dari cetakan masih dalam tahapan pendinginan logam. Uap menimbulkan adanya turbulensi udara yang dapat menghalangi penuangan coran. Ditambah dengan tidak adanya riser kecuali tempat penuangan yang berfungsi sebagai riser juga, menimbulkan cacat pengecoran berupa misrun yang timbul karena udara yang terbentuk didalam dan terjebak. Hasil ditunjukkan Gambar 3. 


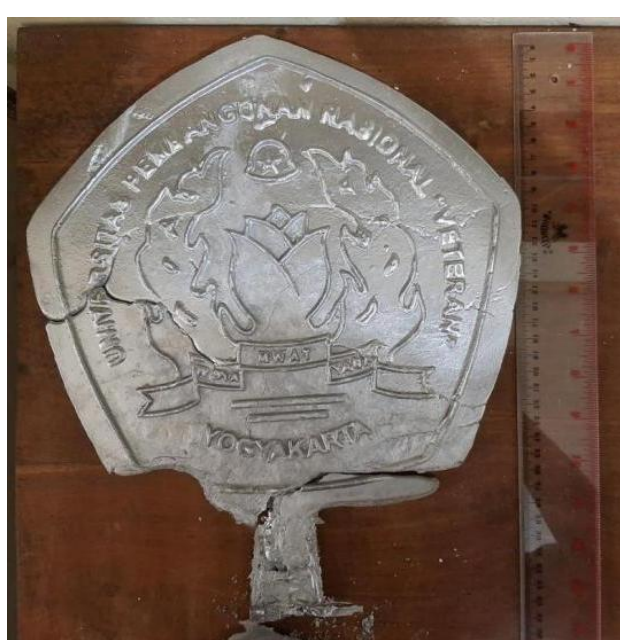

Gambar 3.

Suhu Tuang $650^{\circ} \mathrm{C}$, Suhu Cetakan $170^{\circ} \mathrm{C}$

Sumber: didapatkan dari penelitian, 2021

Keseluruhan pengecoran ini mengalami cold shut dikarena kemiringan cetakan yang terlalu tinggi menyebabkan pergerakan logam cair yang bergejolak didalam cetakan. Suhu tuang $650^{\circ} \mathrm{C}$, dengan suhu cetakan $230^{\circ} \mathrm{C}$ memberikan inklusi kotoran berupa tanah terjadi pada sisi bawah hal ini dikarenakan pembersihan terak tidak ikut terambil maupun terlebur dan mengendap pada bagian tersebut. Tanah tersebut berasal dari sisa pengecoran yang dimasukkan dan belum dibersihkan dari tanah tersebut. Hasil ditunjukkan Gambar 4.

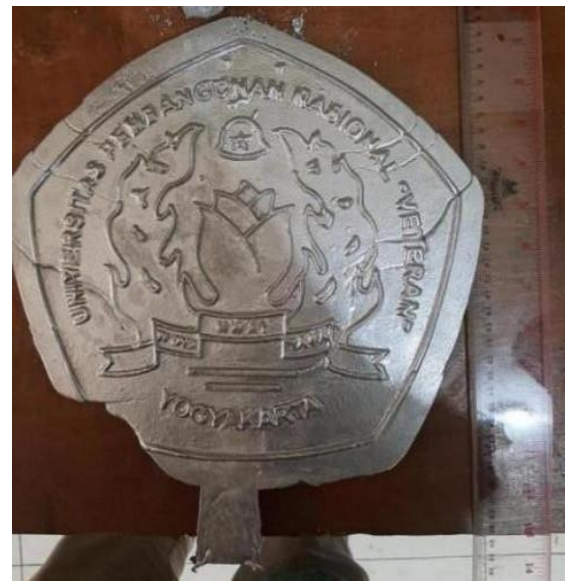

Gambar 4.

Suhu Tuang $650^{\circ} \mathrm{C}$, Suhu Cetakan $170^{\circ} \mathrm{C}$ Sumber: didapatkan dari penelitian, 2021
Suhu tuang $750^{\circ} \mathrm{C}$, tanpa adanya pre-heat didapatkan cacat berupa cold shut pada berbagai sisi hasil coran dikarenakan posisi penuangan sempat terhenti. Crack terjadi akibat suhu penuangan yang kemungkinan terlalu tinggi karena cetakan tidak dilakukan pre-heating sebelumnya membuat logam cair tidak seimbang dengan cetakan. Permukaan yang kasar dikarenakan terak tidak terbuang dengan baik. Pada sisi belakang terdapat inklusi terhadap dinding coran yang diberi lapisan tambahan berupa semen putih. Dengan berbagai penyusutan pada keseluruhan bagian dikarenakan logam umpan tidak tersedia untuk mengimbangi penyusutan ketika logam cair membeku. Hasil ditunjukkan Gambar 5 .

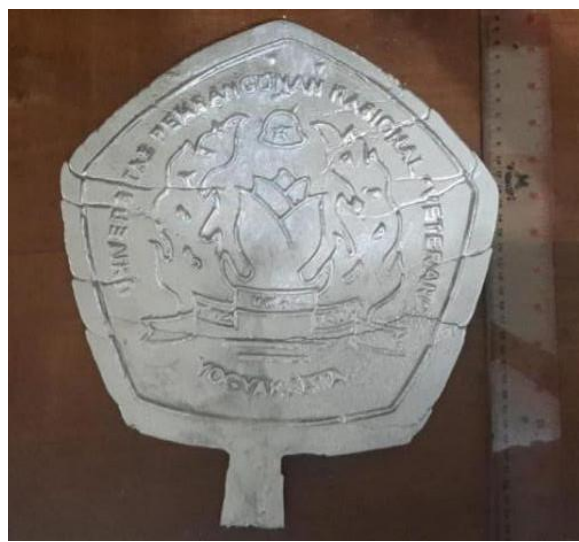

Gambar 5.

Suhu Tuang $750^{\circ} \mathrm{C}$, Suhu Ruang Cetakan Sumber: didapatkan dari penelitian, 2021 Suhu tuang $750^{\circ} \mathrm{C}$, dengan suhu cetakan $150^{\circ} \mathrm{C}$ dilakukan penuangan yang cukup lama serta kondisi operator yang sulit untuk menyesuaikan membuat incomplete casting terjadi. Hasil pengecoran menunjukkan terdapat permukaan yang kasar, shrinkage pada bagian 
tengah, cold shut, maupun porositas. Permukaan kasar terbentuk dikarenakan kandungan aluminium mulai berikatan dengan oksida membuat terak terbentuk. terak terbentuk karena suhu penuangan yang terlalu tinggi yang diharapkan menjadi $780^{\circ} \mathrm{C}$ melambung tinggi hingga $850^{\circ} \mathrm{C}$. Penyusutan ditengah ditimbulkan karena terdapat uap yang ditimbulkan dinding semen maupun dari oli. Kedua hal ini yaitu oli dan semen sudah sangat dikurangi kadar airnya sehingga tidak menimbulkan cacat ini ditambah tidak adanya riser.Hasil ditunjukkan Gambar 6.

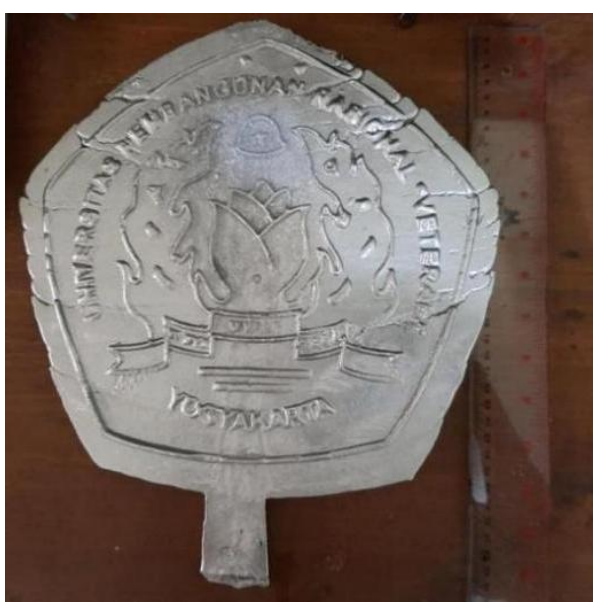

Gambar 6.

Suhu Tuang $750^{\circ} \mathrm{C}$, Suhu Cetakan $150^{\circ} \mathrm{C}$

Sumber: didapatkan dari penelitian, 2021

Suhu tuang $750^{\circ} \mathrm{C}$, dengan suhu cetakan $170^{\circ} \mathrm{C}$ pada saat penuangan operator harus menyesuaikan penuangan saat logam sudah terisi setengah karena sulit keluar dari crucible. Kemungkinan suhu penuangan juga turun secara drastis saat penuangan berlangsung. Warna hitam pada permukaan hasil pengecoran dikarenakan pada dinding cetakan terdapat bekas oli yang sulit dihilangkan. Hasil ditunjukkan Gambar 7.

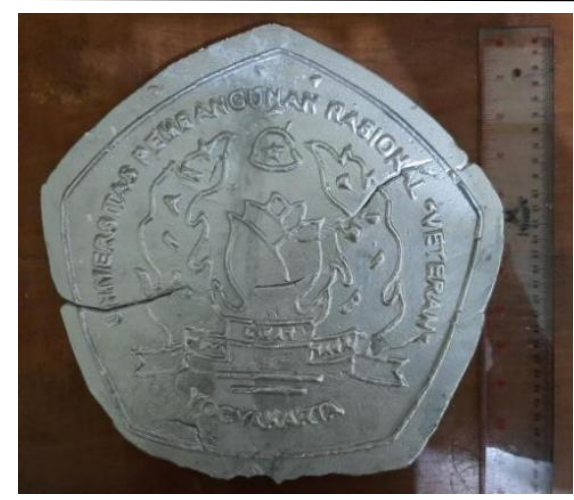

Gambar 7.

Suhu Tuang $750^{\circ} \mathrm{C}$, Suhu Cetakan $170^{\circ} \mathrm{C}$ Sumber: didapatkan dari penelitian, 2021 Suhu tuang $750^{\circ} \mathrm{C}$, dengan suhu cetakan $230^{\circ} \mathrm{C}$ dilakukan penuangan pertama. terjadi kegagalan pada penuangan tersebut dikarenakan saaat penuangan terlalu mengenai dinding cetakan yang bersentuhan langsung dengan udara membuat logam cepat membeku didalam dan menimbulkan incomplete casting. Ditambah selama penuangan didasar crucible logam telah membeku dan membentuk terak. Setelah semua dibersihkan, pengecoran kedua dilakukan. Pada pengecoran kedua oli masih mengganggu dan membentuk misrun. Hasil ditunjukkan Gambar 8.

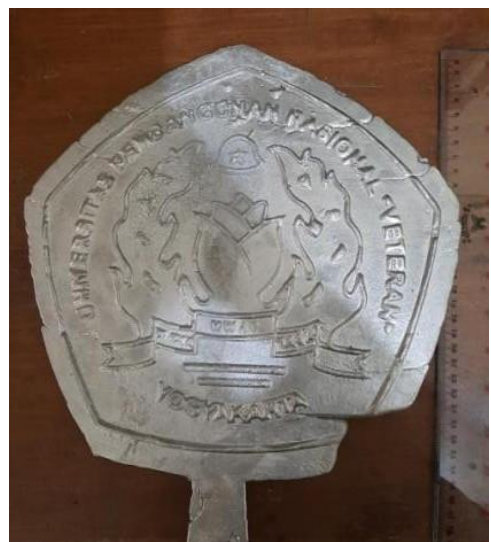

Gambar 8.

Suhu Tuang $750^{\circ} \mathrm{C}$, Suhu Cetakan $230^{\circ} \mathrm{C}$ Sumber: didapatkan dari penelitian, 2021 
P-ISSN: 2723-6854, E-ISSN: 2798-1037

\section{Kesimpulan}

Dari pembahasan dapat disimpulkan sebagai berikut:

1. Suhu penuangan $650^{\circ} \mathrm{C}$ lebih dianjurkan dari pada $750^{\circ} \mathrm{C}$ pada penelitian ini dikarenakan suhu $750^{\circ} \mathrm{C}$ logam cair lebih reaktif terhadap unsur sekitarnya dan membuat terak pada dinding crucible maupun membuat permukaan kasar pada hasil coran. Namun, pada suhu $650^{\circ} \mathrm{C}$ rentan terhadap penurunan suhu yang drastis.

2. Pada penelitian suhu cetakan yang paling baik hasilnya terdapat pada suhu cetakan $150^{\circ} \mathrm{C}$ dari kedua suhu penuangan yang dilakukan. Suhu cetakan $150^{\circ} \mathrm{C}$ tidak menimbulkan misrun maupun incomplete casting yang banyak. Tidak adanya sistem gating menimbulkan misrun pada coran. Suhu cetakan $150^{\circ} \mathrm{C}$ dapat terhindar dari cacat tersebut.

\section{Ucapan Terima Kasih}

Saya selaku penulis mengucapkan terima kasih kepada program studi teknik metalurgi, jurusan teknik pertambangan, fakultas teknologi Mineral, Universitas Pembangunan Nasional "Veteran" Yogyakarta yang telah memberikan kesempatan untuk melakukan publikasi terhadap jurnal ini.

\section{Referensi}

ASTM Internasional. (2003). Standard Specification for Aluminum-Alloy

Die Castings. Diakses dari

https://www.astm.org/b0085_b0085m-

18e01.html.

ASTM Internasional. (2008). Standard Specification for Aluminum-Alloy

Permanent Mold Casting.

Diakses

dari https://www.astm.org/b0108_b01

08m-19.html

Anonim. Wikipedia. American Standard

Testing and Material. Diakses

22 Juli 2021 dari

https://id.wikipedia.org/wiki/

American_Standard_Testing_and

_Material.

Anonim. Wikipedia. Aluminium. Diakses

22 Juli 2021 dari

https://id.wikipedia.org/wiki/

Aluminium\#Sifat_Mekanik_Alu minium.

Budiyono, Aris, dan Widayat, widi.

(2013). Pemanfaatan

Aluminium Skrap Sebagai

Bahan Baku Industri Kecil

Pengecoran Logam

Non ferro Melalui Perlakuan

Pada Logam Cair (Solution

Treatment) Dengan

Rotary Degasser, 1-3.

Butle,W.A, Timeli G., Battaglia E., dan

Bonollo, F.. (2016). Die

Casting (Permanent Mold).

Elsevier.

Campbell, John . (2003). Castings (Second Edition). Elsevier: United Kingdom.

Capuzzi, Stefano dan Timelli, Giulio. (2018). Preparation and Melting of Scrap in

Aluminum Recycling: A Review.

Italy : MDPI, 1-3, 11.

Cholis, Noor Setiawan, Suharno, dan

Yadiono. (2013). Pengaruh

Penambahan Unsur

Magnesium(Mg)TerhadapKekera san dan Struktur Mikro pada

Pengecoran Aluminium, 3-5.

Deter, G. E. (1999). Engineering Design. McGraw-Hill.

D. Oza, Ankit dan Patel,Tushar M. (2013). Analysis and Validation of Gravity Die Casting Process using ProCAST. Gujarat : 
Journal Of Metallurgical Engineering And Processing Technology, Vol. 2, No. 2, February 2022, pp. 21-27

P-ISSN: 2723-6854, E-ISSN: 2798-1037

International Journal of Application or Innovation in Engineering $\&$ Management, 1-2.

E. Dieter George. (1961). Mechanical Metallurgy.

Ghosh and A. K. Mallik. (2001). Manufacturing Science.

John A Schey. (2000). Introduction to Manufacturing Processes, Mcgraw Hill, 3rd Edition.

J. B. Bralla. (1998). Design for manufacturability handbook. New York: McGrawhill handbooks, 2nd edition.

Kridli, G.T. (2020). Materials, Design and

Manufacturing for Lightweight Vehicles (Second Edition).

Kurniawan, Aang, Widyanto S.A, dan Umardhani Y. (2013). Pengaruh suhu Cetakan Pada Cacat Visual Produk Piston dengan Metode Die Casting. Semarang: Jurnal Teknik Mesin Universitas Diponegoro, 2-3, 6-9.

M. F. Ashby. (1999). Material Selection in Mechanical Design.

Otarawanna,S., dan Dahle, A.K. (2011). Fundamentals of Aluminium Metallurgy Production, Processing and Applications. Woodhead Publishing Series.

Rajkolhe, Rajesh dan Khan, J.G. (2014). Defect, Causes and Their Remedies in Casting Process: A Review. Shri Sant Gajanan Collage of Engineering: Shegaon.

Ramadhan, Gilang Fajar. (2020). Tugas Akhir

Pengaruh Variasi Suhu Tuang

Terhadap Tekstur dan Kekerasan

ProdukCor Aluminium Bekas Dengan Metode Sand dan

Lost Foam Casting. Universitas Muhammadiyah Surakarta.
Sanghavi, Chirag, Patil Soham, dan Narayankar S M. (2018). Design and Fabrication of SemiAutomatic Gravity Die Casting Machine, 1. India : International Journal for Scientific Research $\&$ Development.

Satriani, Ajeng Fitria dan Bayuseno, Athanasius priharyoto. (2016). Pengaruh Penambahan Unsur Silikon (Si) pada Shaft Propeller Berbahann Dasar Al-Mg-Si. Semarang : Jurnal Teknik Mesin Universitas Diponegoro, 1, 7.

Sigworth, G. K. (2011). Quality issues in aluminum castings. Fundamentals of Aluminium Metallurgy.

Surdia, Tata, dan Chijiwa, Kenji. (2013). Teknik Pengecoran Logam. Jakarta : PT. Balai Pustaka.

Widodo, Basuki. (2009). Optimalisai Temperatur Pemanasan Cetakan Permanen $\left(300^{\circ} \mathrm{C}, 350^{\circ} \mathrm{C}, 400^{\circ} \mathrm{C}\right)$ Terhadap Sifat Mekanik Paduan Aluminium- Magnesium (SERI 5XXX), 3(166), 9(172). https://doi.org/10.34151/technosci entia.v1i2.393.

Yamagata, Hiroshi. (2005). The Science and Technology of Materials in Automotive Engines. Woodhead publishing.

Zhu, Yongxian, Chappuis Laurent B., Kleine Robert De, Kim Hyung Chul , Wallington Timothy J., Luckey George, Cooper Daniel R. (2020). The coming wave of aluminum sheet scrap from vehicle recycling in the United States, 1-2. https://doi.org/10.1016/j.resconre c. 2020.105208 